QUADERNS DE FILOSOFIA VOL. VI NÚM. 2 (20I9): I I-I 3

eISSN: 234I-3042 DOI: I0.7203/QFIA. 6.2.I605 I

Marta Cabrera, Joan Gimeno-Simó and Saúl Pérez-González

Universitat de València

\title{
The Past and Future of Analytic Philosophy in Spain: XX Years of Taller d'Investigació en Filosofia
}

$\mathrm{T}$

HE Taller d'Investigació en Filosofia is a graduate workshop in philosophy that every year brings together young scholars in order to promote the exchange of ideas with fellow philosophers working on various topics in different areas. Starting out as a local graduate workshop, it has over time attracted an increasingly wider audience, and by the time of its XX anniversary it has become a truly global event that gathers every year participants from all over the world.

The XX edition of the Taller d'Investigació en Filosofia began with an invited talk by Esa Díaz-León, a former participant in the workshop who is nowadays a prominent academic philosopher in Spain. Just like her, several other participants and organisers of previous editions took part in the event by sharing their experience in a round table commemorating its XX anniversary. The presence of these philosophers, currently lecturers and professors, underlines the relevance of this event for the development of analytic philosophy in our country, and for young philosophers who are pursuing a career in the academic world. The Taller d'Investigació en Filosofia has proven to be a place for them to share their ideas, get in contact with fellow researchers and improve their knowledge and skills.

This special issue brings together the work of several participants of the XX edition of the conference. The papers included here are an example of the high quality of the contributions, and they also reflect the interdisciplinary approach of the event, which covers areas from Philosophy of Science to Political Philosophy, as well as Metaphysics, Philosophy of Mind and Language, and Epistemology.

The article by Jansan Favazzo, entitled "Sherlock Holmes Is Not Out There: Some Ideas for A Non-Exoticist Account Of Fictional Characters", 
sets out to provide a semantics for proper names in fiction from the point of view of nominalism and anti-Meinongianism, i.e., without acknowledging the existence of any kind of abstracta. The strategy pursued in this paper is a variant of the Sellarsian metalinguistic account of abstract terms, which deals with statements like "modesty is a virtue" by paraphrasing them away as "all modestwords are virtue-words". Favazzo extends this strategy to fictional proper names: he proposes that their (secondary) extension be understood as a cluster of depictions made in accordance to a certain tradition, and that sentences like "Sherlock Holmes is a detective" be paraphrased away accordingly as "all Sherlock|Holmes-depictions are detective depictions". Throughout the paper Favazzo provides some hints as to how to understand the notions he employs, thus laying the foundations for future work. His discussion briefly covers issues such as the proper way to quantify over fictional characters, when to count a depiction as fictional, including fictional depictions of real characters such as Napoleon in War and Peace, and how to extend his analysis to metatextual statements such as "Sherlock Holmes is a famous character". In sum, the paper sets out a promising approach to the semantics of fictional proper names while at the same time getting rid of any kind of exotic ontological commitment.

Jaime Soler Parra's article, "Defining life as a non-essentialist natural kind", addresses the scepticism about the definition of life and explores the prospects of characterising life as a non-essentialist natural kind. During the last decades, many and diverse definitions of life have been proposed (e.g. physiological definitions, genetic definitions, thermodynamic definitions...). This multiplicity of proposals, and the inherent absence of consensus, have favoured the scepticism about the possibility of defining life. Sceptics argue that life can only be defined in a conventional sense, that defining life is either impossible or pointless, or that every type of life must be considered as an individual. After analysing sceptics' arguments, Soler claims that all of them are based on the same assumption, i.e., defining life requires identifying a basic essential property (or a set of basic essential properties). They are effective only if that requirement is assumed. Subsequently, after showing that sceptics' assumption does not suit scientists' practice, he explores the possibility of defining life in a non-essentialist way. Within this framework, most proposals have characterized life as a homeostatic natural kind. However, that approach has outstanding difficulties in accounting for life. Soler argues that a more promising strategy would be to define life as a promiscuous natural kind. Promiscuous natural kinds not only are compatible with the diffuse limits of the notion of life and the fact that kinds are not always defined in exactly the same way, they also account for scientists' use of the concept of life. In his article, Soler also discusses the relevance and utility of defining life for 
scientific research. He considers that it is useful for guiding scientific research and avoiding confusing results.

Finally, in "The Egalitarian Quality of Lottocracy", Julia Jakobi explores the way in which lottocratic systems, where politicians are randomly selected out of the totality of citizens entitled to vote, could satisfy the egalitarian requirement of democracy. There is broad consensus on the idea that democracy is the most desirable politic system available. Authors have argued for its value on the grounds of instrumental or egalitarian reasons: democratic decisionmaking tends to render good and epistemically valuable results and democracy is a source of political equality. The proponents of lottocratic models, however, claim that replacing the right to vote by the chance to be selected can satisfy both the epistemic and egalitarian values of democracy. Jakobi focuses on the latter and argues that, in addition to improving the representation of the population and reducing undemocratic influences, as some proponents have pointed out, having a chance to be selected by lot satisfies the intrinsic value of democracy in a relevant way. It does so by enhancing political justice and providing citizens with an equal chance on political influence. After examining the reasons why political equality is considered a key element of a desirable political system, Jakobi addresses two possible ways in which we can understand such notion. She holds that political equality can be conceived of as political justice and as vertical equality of influence, and provides arguments that show that a lottocratic system satisfies them both.

During the last two decades the Taller d'Investigació en Filosofia has served as a forum of discussion and exchange for the younger generations of academic philosophers in Spain. It has fueled the academic career of many former participants who have seen their work published as a result of the valuable feedback and new ideas they received. We hope that this workshop will continue to perform such significant role for future generations in philosophy to come.

\section{Acknowledgments}

Marta Cabrera is supported by the Spanish Ministry of Science, Innovation and Universities under grants BES-2017-081537 and FFI201675323-P. Joan Gimeno-Simó is supported by the European Social Fund and the Conselleria d'Educació of the Valencian Community under the grant ACIF/2016/421. Saúl Pérez-González is supported by the Spanish Ministry of Science, Innovation and Universities under grants FPU16/03274 and FFI2017-89639-P. 
